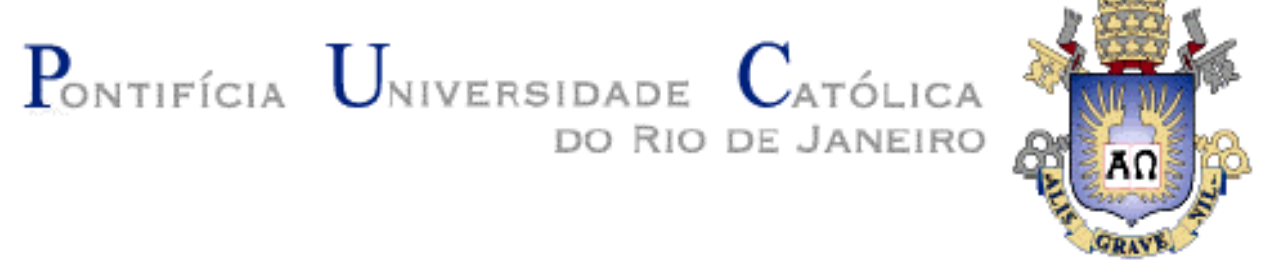

Cynthia Storck Figueira

\title{
Motivação de Compra Hedônica ou Utilitária: Como Afeta o Arrependimento?
}

\section{Dissertação de Mestrado}

Dissertação apresentada ao Programa de Pósgraduação em Administração de Empresas da PUCRio como requisito parcial para obtenção do título de Mestre em Administração de Empresas.

Orientador: Prof. Luis Fernando Hor-Meyll Alvares

Rio de Janeiro

Julho de 2010 


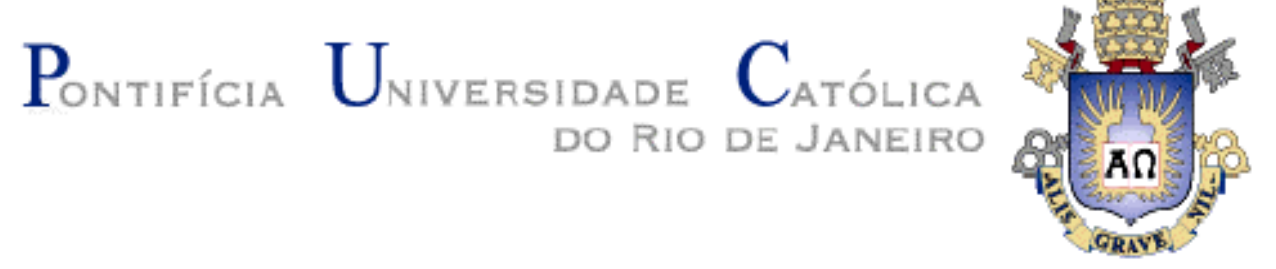

Cynthia Storck Figueira

\section{Motivação de Compra Hedônica ou Utilitária: \\ Como Afeta o Arrependimento?}

Dissertação apresentada como requisito parcial para obtenção do grau de Mestre pelo Programa de Pósgraduação em Administração de Empresas da PUCRio. Aprovada pela Comissão Examinadora abaixo assinada.

Prof. Luis Fernando Hor-Meyll Alvares

Orientador

Departamento de Administração - PUC-Rio

Prof. Paulo Cesar de Mendonça Motta

Departamento de Administração - PUC-Rio

Prof. Victor Manoel Cunha de Almeida

COPPEAD - UFRJ

Profa. Mônica Herz

Vice-Decana de Pós-Graduação do CCS

Rio de Janeiro, 09 de julho de 2010 
Todos os direitos reservados. É proibida a reprodução total ou parcial do trabalho sem autorização da autora, do orientador e da universidade.

\section{Cynthia Storck Figueira}

Graduou-se em Comunicação Social - Publicidade e Propaganda na UFF (Universidade Federal Fluminense) em 2000. Pós graduou-se em Marketing no IBMEC Business School em 2006.

Ficha catalográfica

Figueira, Cynthia Storck

Motivação de compra hedônica ou utilitária: Como afeta o arrependimento? / Cynthia Storck Figueira; orientador: Luis Fernando Hor-Meyll Alvares. - 2010.

61f. : il. ; $30 \mathrm{~cm}$

Dissertação (mestrado) - Pontifícia Universidade Católica do Rio de Janeiro, Departamento de Administração, 2010.

Inclui bibliografia

1. Administração - Teses. 2. Arrependimento. 3. Motivação hedônica. 4. Motivação utilitária. 5. Avaliação pós-compra. I. Hor-Meyll, Luis Fernando. II. Pontifícia Universidade Católica do Rio de Janeiro. Departamento de Administração. III. Título.

CDD: 658 
Aos meus pais que dedicaram a história de suas vidas à construção do meu caráter...

...Valcir e Vera Lúcia. 


\section{Agradecimentos}

Primeiro, a Deus, por sempre iluminar meu caminho.

Ao programa de Mestrado em Administração da Escola de Negócios da PUC do Rio de Janeiro, a todos os seus profissionais e professores, pela qualidade de ensino e pesquisa.

Ao Professor Luis Fernando Hor-Meyll, pela disponibilidade, ensinamentos e orientações, que deram norte a este trabalho, facilitando alcançar os seus objetivos. Seu incentivo, amizade e respeito foram cruciais para que eu acreditasse na minha capacidade de ir além.

Ao Professor Paulo César Motta da PUC-RJ, pela sabedoria compartilhada nas aulas do mestrado e pela sua presença nesta banca que, com certeza, contribuirá para ampliar a qualidade deste trabalho.

Ao Professor Victor Manoel Cunha de Almeida da COPPEAD-UFRJ, por participar desta banca, pelo seu conhecimento e disposição que, certamente, tornarão este trabalho mais rico.

Ao Professor Jorge Brantes, por analisar, gentilmente, os dados da pesquisa e sugerir importantes melhorias.

Aos professores, alunos e profissionais que participaram direta ou indiretamente deste estudo, especialmente, aqueles que compartilharam comigo o aprendizado, as angústias e as alegrias: Juliana, Suzane, Mariana e Labruna. Aos funcionários da secretaria acadêmica do IAG PUC-RJ, em especial, à Teresa Campos e ao Fábio Etienne, pela competência e sincera dedicação. À Mônica Noronha e Magda Fleur, que gentilmente, me ajudaram no envio do questionário.

Aos meus companheiros de trabalho, que me incentivaram e me auxiliaram, em especial, ao Rogério Quintanilha, que me ajuda a superar os desafios profissionais e de vida, com alegria, gentileza, leveza e bom humor.

Aos meus amigos, que me motivaram nesta importante etapa, estando ao meu lado sempre que precisei de ajuda, carinho e “colo”. Em especial, à Patricia Amorim, agradeço por ser instrumento de Deus no meu caminho.

Aos meus pais, que estiveram sempre ao meu lado, me incentivando a estudar e fornecendo suporte para isso. Ambos me deram a mais valiosa aula, que faculdades não são capazes de dar: amor, valores e princípios. Aos meus amados irmãos Ticiane e Alessandro. Sou grata a Deus por ter vocês na minha vida. 


\section{Resumo}

Figueira, Cynthia Storck; Alvares, Luis Fernando Hor-Meyll. Motivação de Compra Hedônica ou Utilitária: Como afeta o arrependimento? Rio de Janeiro, 2010. 61p. Dissertação de Mestrado - Departamento de Administração, Pontifícia Universidade Católica do Rio de Janeiro.

As motivações hedônica e utilitária de compra podem provocar diferentes reações emocionais na avaliação pós-compra, como arrependimento. A abordagem do arrependimento como uma emoção negativa, fruto do processo de avaliação pós-compra, vem ganhando mais atenção e importância no estudo do comportamento do consumidor. Esta dissertação procurou examinar como se manifesta o arrependimento que consumidores experimentam na avaliação póscompra, em função de sua motivação de consumo ser hedônica ou utilitária. Conduziu-se um levantamento (survey), com o questionário sendo enviado por email para uma amostra não-probabilística de 131 consumidores. Os resultados encontrados sugerem que o arrependimento experimentado manifesta-se de forma mais intensa quando a motivação da compra for hedônica e menos intensa quando a motivação de compra é utilitária.

\section{Palavras-chave}

Arrependimento; motivação hedônica; motivação utilitária; avaliação póscompra. 


\section{Abstract}

Figueira, Cynthia Storck; Alvares, Luis Fernando Hor-Meyll (Advisor). Hedonic or Utilitarian Purchase Motivation: How does it affect regret? Rio de Janeiro, 2010. 61p. MSc. Dissertation - Departamento de Administração, Pontifícia Universidade Católica do Rio de Janeiro.

The hedonic and utilitarian motivations of purchase can provoke different emotional responses in post-purchase, such as regret. The regret's approach as a negative emotion, the result of the evaluation process after purchase, is gaining more attention and importance in the study of consumer behavior. This dissertation attempted to examine how it expresses regret that consumers experience in post-purchase, depending on their motivation for consumption is hedonic or utilitarian. We conducted a survey, with the questionnaire being sent by e-mail to a non-probabilistic sample of 131 consumers. The results suggest that experienced regret is manifested more intensely in the hedonic motivation of purchase and it is less intense in the utilitarian motivation.

\section{Keywords}

Regret; hedonic motivation; utilitarian motivation; post-purchase evaluation. 


\section{Sumário}

1. Introdução 13

1.1. Definição do problema $\quad 15$

1.2. Objetivo do estudo 16

1.3. Relevância do estudo 16

1.4. Delimitação do estudo 17

$\begin{array}{ll}\text { 1.5. Organização do estudo } & 17\end{array}$

2. Revisão da literatura 19

2.1. Dimensões hedônica e utilitária do consumo - uma visão geral $\quad 19$

2.1.1. Motivações hedônica e utilitária na compra de produtos 21

2.1.2. Motivações hedônica e utilitária na compra de serviços 24

2.2. Arrependimento na avaliação pós-compra 27

2.2.1. Arrependimento - uma visão geral 28

2.2.2. Diferenças entre arrependimento e desapontamento 30

2.2.3. Arrependimento experimentado 31

2.2.4. Arrependimento e motivações hedônica e utilitária de
compra

2.3. Hipótese 33

3. Método 35

3.1. Tipo de pesquisa $\quad 35$

3.2. Escolha das categorias de consumo $\quad 35$

3.3. Operacionalização das variáveis da pesquisa 36

3.3.1. Operacionalização da variável motivação de compra
(hedônica e utilitária)

3.3.2. Operacionalização da variável arrependimento
experimentado

3.4. Construção do instrumento de medida 38

3.4.1. O instrumento de coleta de dados 38

3.5. Amostra 39

3.6. Coleta de dados $\quad 40$

3.7. Limitações do método 40

4. Análise dos dados 41

4.1. Resultado da $1^{\mathrm{a}}$ etapa exploratória do estudo 41

4.2. Caracterização da amostra 42

4.3. Análise das dimensionalidades dos construtos 42

4.3.1. Motivação de compra 42

4.3.2. Arrependimento experimentado $\quad 44$

4.3.3. Teste da hipótese 46 
5. Conclusões 49

5.1. Sumário 49

5.2. Conclusões 49

5.3. Sugestões para pesquisas futuras 52

6. Referências bibliográficas 53

7. Anexos 59

7.1. Anexo I - questionário da pesquisa 59

7.2. Anexo II - questionário escolha categorias
(fase exploratória) 


\section{Lista de figuras}

Figura 1 - Médias de arrependimento experimentado 


\section{Lista de quadros}

Quadro 1 - Itens da escala HED/UT de Voss et al. (2003)

Quadro 2 - Itens da escala de arrependimento de

Zeelemberg e Pieters (2004)

38

Quadro 3 - Sumário das escalas utilizadas para

operacionalização das variáveis 


\section{Lista de tabelas}

Tabela 1 - Caracterização da amostra 42

Tabela 2 - Resultados da análise fatorial de hedônico/utilitário 43

Tabela 3 - Médias pareadas de hedônico/utilitário 43

Tabela 4 - Teste t para diferença das médias entre hedônico x utilitário por categoria de produtos e serviços 44

Tabela 5 - Resultados da análise fatorial de arrependimento $\quad 45$

Tabela 6 - Confiabilidade de hedônico/utilitário 45

Tabela 7 - Confiabilidade de arrependimento 46

Tabela 8 - Resultado da diferença de médias de

\begin{tabular}{ll} 
Tabela 9 - Médias de arrependimento & 46 \\
\hline
\end{tabular}

Tabela 10 - Teste t para diferença das médias de 